\title{
Significance of Technology and Digital Transformation in Shaping the Future of Oil and Gas Industry
}

\author{
Shubham Parsoya ${ }^{a}$, Dr. Asif Perwej \\ ${ }^{a}$ Research Scholar, School of Management Studies Sangam University, Bhilwara, Rajasthan, India \\ ${ }^{\mathrm{b}}$ Associate Professor, School of Management Studies Sangam University, Bhilwara, Rajasthan, India \\ ashubhamparsoya369@gmail.com, bdr.asifperwej@gmail.com
}

Article History: Received: 10 November 2020; Revised 12 January 2021 Accepted: 27 January 2021; Published online: 5 April 2021

\begin{abstract}
Digital transformation in the field of oil and Gas industry is already a significant impact creator. It is actually act like catalyst through which the overall functionality of the oil and gas industry get enhanced and the overall output with the help of technologically-advanced mechanism, increased up to manifold. In the present scenario, the over-all quest is not just about the volume of the oil and petroleum, but it is also regarding the overall value generated throughout the process. And such enhanced level of value generation is taking place with great pace with the help of enhanced level of implementations of different types of technologies in different type of activities related to the oil and gas industry. In the present scenario, oil and gas industry's business model is no longer depending upon just the inflated and narrow based value-chain mechanism. It is actually depending upon the almost all modernized and futuristic technologies. The modern technologies include big data analytics, 3D printing technology, cyber security, digital marketing, Artificial Intelligence, Internet of Things, drone technologies, database management system, etc. all these technologies are not only supports in handling the overall business capability of the oil and Gas Industries, but also eliminate the overall negative impact generating elements. With the help of technologies and digital transformation, the overall profitability of the oil and gas industry enhanced. Digital transformation is a prominent and significant impact creator which is not limited to the oil and gas industry, but also reaching up to the all-global level Businesses. It is transforming the overall business operations by enhancing the speed of innovation and making the use of practical knowledge base which ultimately enhance the overall power of operations and increase efficiencies. With the emergence of digital transformation technologies especially with the emergence of big data analytics, the Internet of Things and Artificial Intelligence have supports several types of innovative and new ways of developing and transforming the overall market as well as the customer satisfaction in significant manner. All such innovative technologies and digital transformations are contributing significantly in shaping the future of oil and gas industry.
\end{abstract}

Keywords: digital, transformation, oil, gas, economy, industries, businesses, technology

\section{Introduction}

The oil and energy industry are one of the most important industry in the whole world as almost all the top economically advanced nations have direct or indirect linkage with the processing and marketing of oil and Gas based products such as China, United State of America, United Kingdom, United Arab Emirates, Abu Dhabi, Russia, etc. But because of the happening of an uncertain and unexpected incident of Covid-19, not only the oil and gas industry but almost each and every industry including textile-based Industries, communication-based Industries, transportation Industries, tour and travel industry, manufacturing industry, supply-chain industry, and all other industrial's functioning hampered significantly for a very long period of time. With problems come into consideration, it will also create an opportunity for analysing the situations and come up with new learnings and opportunities of making the things again under controllable condition with more advanced level of performance in working, which was somehow hampered because of the negative impacts of bad incident such as Covid-19.

Due to the overall negative impacts spread all around the whole world in the pandemic situations which was created because of covid-19, oil and gas industry functionality was affected for almost 5 to 6 months of time on a continuous basis. Each and every individual who was in some of the way related to the businesses of oil and gas industry were facing different level of complexities in terms of their working. For instance, if we take into consideration overall businesses of the retail outlet owners which were previously the incidence of covid-19, earning a very good amount of profit through their businesses, were somehow not at all able to manage the salary of their own staff for almost 5 to 6 months of time. In the same manner, if you consider the overall demands of the daily customers of oil and Gas based products, they are also facing the level of complexity in terms of buying and fulfilling the oiland petroleum-based demands, because of the lockdown procedure spreading all around the globe. 
In handling such complex situations, there are almost all individuals who faced complexities in terms of their businesses, works, and functionality, some very new concepts as well as plans come into consideration which is mostly technologically-driven and digital-based strategies. Technology is like a catalyst, it can enhance the overall working of almost each and every type of activity including the oil and gas industry. With the help of proper implementation of such technologies in the recent times as well as in the near future also, our world will be able to function with almost ten times more pace in terms of businesses of oil and gas industry. Some of such advanced and modern technologies are Big dataanalytics, Artificial Intelligence, digital marketing, cloud computing, drone technology,Internet of Things, Etc.

\section{Literature Review}

As per the study conducted by Mehndi Mohammadpoor and Farshid Torabi and published in the journal titled KeAi Chinese Roots Global Impact, under the guidance of the faculty of engineering and the applied science, the University of Regina, Canada with the research paper titled Big data analytics in oil and gas industry: An emerging trend, under the guidance of Southwest Petroleum University. The research paper analyzes the importance of the utilization of big data analytics. Big data analytics is an emerging trend in the field of concerns that are related to the different aspects of Oil and Gas industry. The paper shows that Big data analytics is a modern technology that can be used for handling very big data sets in a diverse manner. Also, analyze the different types of data characteristics which vary from volume, velocity and complexity.

The research paper signifies the current advent of the recording of data through sensors in the field of different types of activities which are performed under oil and gas industry, such as exploration, drilling processes, production activities, operational activities, and all such activities which consist of a big amount of data which ultimately encourages the significance of data industry. The research paper also highlights the importance of Big data analytics and related technology in enhancing the overall reservoir characterization and in reducing the overall drilling time with an enhanced level of safety standard. The research paper also focuses on the optimization capabilities of Big data analytics in increasing the performance of production pumps, improving the shipping and transportation of oil and gas, etc. The paper also highlighted the various level of challenges which are still faced by different businesses and industries by not utilizing the Big data analytics for their business. It also highlights the importance of understanding as well as awareness programs regarding proper implementations of Big data analytics.

\section{Significance of the Study}

Technologically-driven and digital transformation are taking place in almost all types of activities. In the current scenario, no one can think about the world's functionality without the presence of technology-based development. Almost each and every activity that a man is performing in this 21 st century from waking up to going to the bed, whatever activity comes in between these two points of time consists of different types of technological-based gadgets, software, instruments, etc. for making the whole lifestyle of human being much easier, productive and efficient. Technology is the future, as we all already know and understand very well. But, in what possible way we are using our current technology is not at all the end in terms of it, as there is no concept available in terms of boundaries when we consider the functionality and coverage area of technology. Along with new and modern technology the changes also taking place in the field of the digital world. The digital world is mainly consisting of the power of digitization of different types of activities and functions which are directly and indirectly related to the human functions and the mechanism which are related to the human activities.

As the network and internet advancement taking places in achieving the target of fast pace of processing data, all other activities which were performed by the human in terms of their daily and official activities such as documentation, communication, transportation, businesses, industries, and all other activities are directly transformed and advanced with the introduction of the new era of advanced technologies. Technological development is also taking place in the oil and gas industry. The oil and gas industry are one of the biggest industries in the whole world. No, any single nation can think about their functionality without the presence of proper oil and place fulfilments. The way in which the blood circulates in our veins and arteries throughout the body and make our body capable of doing a different set of functions, in the same manner the oil and gas industry act like a the key most element in running the whole workings of each and every Nation, For example Transportation, Businesses, Industries, Energy Industries, Petroleum Industries, Tourism and Travelling Industries, our daily transportation needs through our private vehicles, Public Transportation, Etc. Not a single person can think about their life without the availability of Oil, Petroleum and Gas Industry at least for the now, till any new and comparatively advance industry come under considerations, which can replace the oil Petroleum and gas industry in the near future but as per now oil and gas industry will be the top energy-based industry for almost next 100 years of time. 


\section{Methodology}

As per the needs and requirements of the research work and analytical study, the analysis come into implementation for the study of the stated topic is done in the thorough and descriptive manner with the help of various types of information and data collected. For this reason, the all possible and required level of secondary data-based information was all at once and broadly used for the analysis purpose. A lot of detailed and distinguished level of swotting processes was come into consideration for accessible data and its in-depth investigation associated with the topic and related data. For the analysis\& the study of the Significance of Technology and Digital-Transformation in Shaping the Future of Oil and Gas Industry, the research paper relies on the research which is directly connected and completely depending upon the information and data received and sourced from various libraries, books, important notes,documents, data from various national and international journals, different types of magazines, germane books, topic concerning articles, reports, media resources, Etc.

\section{Analysing The Role Of Technology In Enhancing The Growth Of Oil And Gas Industry}

There are several technological development taking places every year.In which the most emerging and the most advanced technologies of recent times includes Artificial Intelligence, Big data, the Internet of Things, 3D printing, cybersecurity, cloud computing, etc. The oil and gas industry are a type of industry which is working for a very long period of time, and in its overall working till the current time faced several types of changes and challenges already taken place in its operations. Traditionally, the drilling process of crude oil was operated through the manpower implementations, then after some time the changes takes place and due to which several types of machinery and mechanical instruments came into consideration.

But due to the emerging exploration and enhancement taking place in the all working limits of oil and Gas Industries, there is a huge requirement taking place in terms of increasing the overall productivity and efficiency of the overall oil and gas industry business. Due to the continuous increments taking place in the overall demand for oil and Gas products all over the world, the overall available amount of good and services produced is somehow not at all sufficient to fulfil the overall needs and requirements of the globe level. And by implementing and utilizing the traditional technological base, the oil and gas industry will somehow not able to fulfils the overall future demands in the field of petroleum and gas requirements. The oil and gas industry needs some type of advance and futuristic technology through which it can enhance the overall productivity levels of its goods and services as well as reduce the overall costing and negative impacts regarding the same, which are somehow hampering the overall growth of the oil and gas industry. As per the current scenario, Artificial Intelligence technology which is act like a helping and supporting hand for the different businesses like oil and gas industry. Most significantly, Artificial Intelligence technology will help the oil and gas industry in solving several challenges and problems in a diverse manner. The modern technology of Artificial Intelligence is so much emerging and developing that its global market capital will be expected to reach up to 3.81 billion United States Dollar in the terms of money by the year 2025, which was valued at approximately 2 billion United States Dollar in the year 2019.

As we all know that, the oil and gas industry is among the most profitable industries as well as the most dangerous industry too. There are several types of dangers which can be capable of taking place without giving any type of intimations specially in the oil and gas industries. But artificial intelligence technology can help oil and gas industry business operations in optimizing the overall performance and productivity level along with handling the overall safety standards.

The overall mechanism of the oil and gas industry pipeline are very much complex and problematic. Several times, it will be a very complex task for the manpower working in the oil and gas industry, to identify the overall improper connectivity in pipelines and detecting the overall defects present in complex and error-prone mechanisms. Due to the complex mechanism, most of the time some types of minor mishaps taking place at the refineries of oil and gas industry.But with the help of artificial intelligence, it will become so much easy to detect and analyse the overall defects in the oil pipelines and machines in the stipulated manner.

With the help of artificial intelligence, the overall functioning of oil and Gas Industries can be managed through a computer vision-based system. Search computer-based vision system can easily verify the overall quality of production and deploy deep insight into the overall functioning and analyse the defects taking place. The Artificial Intelligence protection system is cost-efficient and economical in terms of installation and operations in comparison with the all previously installed mechanism used by the oil and gas industry. Oil and gas plants function in very extreme environmental conditions. Extreme environmental conditions may create several types of risk which can be results into different types of injuries to the workers and employees who are working in the oil and gas plants. One of such kind is the extreme temperature levels under which the employees are working continuously. 
Several types of hazardous and harmful gases are continuously emitting at such Oil and gas plants, which can easily make people ill. For the overall safety of the employees working in such a critical environment, different types of rules and regulations already introduced by the governments of different countries. But somehow the departments sometimes not fulfil such norms as required. But with the help of Artificial Intelligence, there are several monitors system which can be installed at the oil and gas plants through which the surveillance process can be managed. With the help of Artificial Intelligence technology, the overall safety of the labour, worker, and employees can be easily enhanced up to certain level. As artificial intelligence makes checks over the proper implementation of the rules and regulations, almost all the employees and workers working in hazardous environments will follow the rules and regulations and wear proper personal protection equipment.

Artificial intelligence technology can also help the overall oil and gas industry business in reducing the overall cost of production and cost of maintenance. The global market capital will be expected to reach up to 3.81 billion United States Dollar in the terms of money by the year 2025. As oil and gas operation is based on storage system, which stores the extracted crude oil. Oil rigs which are installed in the overall repository will work as a distributional mechanism, but because of the continuous utilisations and extreme temperatures under which it is operating, different types of problems taking place including corrosion of the oil rigs.The degradation of the oil rigs can weaken the overall pipeline system and it will also result in deformation. But the artificial intelligence can easily prevent such type of incidents before their actual occurrence. Here for safeguarding the overall procedure two different types of technology come into consideration which is, Artificial Intelligence technology and Internet of Things technology. The combination of these two technologies can help in detecting the early signals of corrosion occurrence with the help of several parameters and predictions. The modern technology of Artificial Intelligence is emerging and growing significantly in the market of Asia-Pacific, Whereas its largest market place is in North America and the overall CAGR is $10.15 \%$ as per the report of 2020.

Artificial Intelligence technology and Internet of Things technology jointly work like protecting mechanism through which the big mishaps can be controlled and can be managed before its actual occurrence.The oil and gas industry business completely deals with various types of routine decision making which are very significant and important from the business point of view, any single wrong decision can impact the overall oil and gas industry business, drastically. For enhancing the overall analytics and interpretation of proper decision making, different and modern technologies come into consideration which is Big data analytics technology and Artificial Intelligence applications-based technologies. The global market capital of modern technology Artificial Intelligence was valued at approximately 2 billion United States Dollar in the year 2019.

Most of the industries which are dealing in the oil and gas business are utilizing these two technologies in deriving useful data and information on which several types of different segments are covered in well-managed patterns on the basis of which proper predictions can be made.The combination of these two technologies along with the algorithm will enhance the overall decision-making capabilities of such Oil and Gas Industries. Such technologies will help in analysing the different types of data in real-time analytics which will generate different types of intelligence-based suggestions and recommendations through the computer system. In such a way, Artificial Intelligence technology and Big data analytics can enhance the strategic decision-making capabilities of Oil and Gas Industries which will directly help in improving the overall operational efficiencies and it will reduce the chances of failures, and also help in reducing the overall production cost.

\section{Highlighting The Importance Of Digital-Transformation In Shaping The Future Of Oil And Gas Industry}

Digital transformation is assessing towards capturing the global businesses and industry in a dominating manner. Digital transformation is actually the changes that are produced by the changes implemented in the application of digital technology which can be spread to the whole society. In the current scenario, each and everything which of human can performs on daily basis can be easily managed through a smartphone connected with internet. Digital transformation is not just about the smartphone and the internet, it is actually more than this. But when we reconsider a mass level of society that is connected with several different businesses and industries, then in such areas smartphones and internet connectivity are the two key technologies, which can change the whole world, significantly. Modern technology development is actually the real player of the whole game. The businesses which are moving towards digitization and are converting themselves towards the digital world will get a sure chance of not only winning the near future but also ruling the whole world, right now.

Digital transformation is one of the most important tools through which several significant changes take place in the business models of several Industries including the oil and gas industry. It enhances the overall speed of innovation and development. With the help of business transformation, several industries will get a chance of regaining their lost market share as well as supports in introducing and capturing several market areas that are right now, untouched. 
Digital transformation will make it possible to gain the practical level of working capital as well as help and initiating the effectiveness and efficiencies of overall business operations. It also helps in analysing the procedures through which different types of segments can be managed and control. It helps in actualizing the different roles which are related to the development, supply, and activities which are related to customer relationship. Digital transformation also helps in capturing significant areas of the market with ease. It helps in asserting the various innovative ways through which the oil and gas industry transforms the customer and the public relation.

Big data analytics is one of the most important supporting hand in the development of the futuristic Oil and Gas industry. With the help of Big data, several companies and industries are gaining advantages in the field of market capturing, profit enhancement and customer satisfaction. Big data analytics is a smart data processing application through which data is analysed on a deep basis because of which an algorithm is generated through which the computer technology can analyse and assess various types of solutions of different market complexities and questions. The collected data is processed thoroughly in the mechanism for the purpose of gaining the output which will help in policy formulation and strategic planning development.

Several types of data are being collected by different types of sources which can be processed with an ultimate aim to analyse the current market trend. The company which has better data utilizing and analysing capabilities will get an edge over all other competitors, because the one who has performed in improved mannan and has a high level of pace in capturing the overall effect of automated data processing system will become "the winner of the future". With the help of emerging digital technologies as well as a decrease in the overall cost of data processing, the mass level of population is now in reach of high-speed data. And different types of changes also taking place in terms of the improvement in the internet bandwidth as well as the enhancement in the performance of sensors. All such technologically advanced level of developments helps the whole world to remain connected and linked with the digital economy base, almost all the time. All search will ultimately result in building up a very strong and powerful digitally advanced and innovative oil and gas industry connectivity network.

\section{Conclusions}

In this research paper, a study was conducted on the significance of technology and digital transformation in enhancing the working capacity of Oil and Gas industry. The Oil and Gas industry is a very big industry and because of its big size, all the decisions and policy implementation regarding the operation of Oil and Gas industry is somehow very much complex task. There are various type of activities which are taking places in the overall working of Oil and Gas industry. As per the traditional method, all the functioning and activities of Oil and Gas industry mostly control and manage by human resources. Human resource is functioning in the best possible way, but somehow there are certain chances remains where there is a possibility of some mistake take place in the functioning of the oil and gas industry. In any case, a single mistake done by the human being in the oil and gas refinery will ultimately result in a huge loss of not only the Oil and Gas industry but also the human resources. Elimination of such mistakes is completely possible with the help of technology. As technology works according to the commands given to the system. Because of such mechanism, there is almost no chance of mistakes taking place by the machines and instruments. It doesn't mean that all the activity can only be done just by the machines and technology. The best possible way of performing any task is by combining the two significant and workfocused elements. Here these two significant elements are the human being and technology. With the help of a combination of these two elements, we can get the best possible result in the field of Oil and Gas industry. With the emergence in the field of technological development, there are several different types of technologies available in the whole world which are highly capable of performing the various type of task in best possible ways. Some of such advanced and modern technologies are Big data analytics, the Internet of Things, Digital Marketing, 3D printing, Artificial Intelligence, Etc.The global market capital of modern technology of Artificial Intelligence was valued at approximately 2 billion United States Dollar in the year 2019. And it will be expected to reach up to 3.81 billion United States Dollar in the terms of money by the year 2025.

The modern technology Artificial Intelligence is emerging and growing significantly in the market of AsiaPacific, Whereas its largest market place is in North America and the overall CAGR is 10.15\% as per the report of 2020. With the helped of these advanced technology, Oil and Gas industry can enhance it's working capability by manifold. There are different types of technologies that are already implemented by the Oil and Gas industry, but there are a lot more which are still remain to be utilized till now. One of the most important reasons behind not implementing such technology are unavailability of the required level of knowledge and the lack of awareness and practicality in terms of implementing such modern and advanced technology for the betterment of the Oil and Gas industry business. The Oil and Gas industry can easily spread its impact over a mass level for a significantly long period of time even in the presence of several other competing industries entering into the market. For surviving in the long run as well as emerging and growing accordingly, the proper utilization of technology is very much important for the Oil and Gas industry. 


\section{References}

Accenture, GE and Accenture Announce Columbia Pipeline Group First to Deploy Break-Through "Intelligent Pipeline Solution" [Press release], 6 January 2016, https://newsroom. accenture.com/news/ge-and-accentureannounce-columbia-pipeline-group-first-to-deploy-break-through-intelligentpipeline-solution.htm.

Accenture, The 2016 Upstream Oil and Gas Digital Trends Survey, https://www.accenture.com/chen/insight2016-upstream-oil-gas-digital-trends-survey

Al-Mansour, J., \& Al-Ajmi, S. (2020). Coronavirus 'COVID-19' - Supply Chain Disruption and Implications for Strategy, Economy, and Management, Journal of Asian Finance, Economics and Business, 7(9).

Allan, Phil, "North Sea operators team up to reduce warehouse stock", Energy Voice, 21 March 2016, https://www. energyvoice.com/oilandgas/north-sea/104585/north-seaoperators-team-reduce-warehousestock/.

Bacq, S., Geoghegan, W., Josefy, M., Stevenson, R., \& Williams, T. A. (2020). The COVID-19 Virtual Idea Blitz: Marshaling social entrepreneurship to rapidly respond to urgent grand challenges. Business Horizons.

Caineng Zou, Zhi Yang, Shizhen Tao, et al.Nano-hydrocarbon and the accumulation in coexisting source and reservoir Petroleum Exploration and Development, 39 (1) (2012), pp. 13-26

Cankurtaran, P., \& Beverland, M. B. (2020). Using design thinking to respond to crises: B2B lessons from the 2020 COVID19 pandemic. Industrial Marketing Management, 88, 255-260.

Chesbrough, H.; Vanhaverbeke, W. \& West, J. Open Innovation: Researching a New Paradigm, Oxford University Press, 2006

Crick, J. M., \& Crick, D. (2020). Coopetition and COVID-19: Collaborative business-to-business marketing strategies in a pandemic crisis. Industrial Marketing Management, 88, 206-213.

Dutta, Kunal, "Grand Designs: How 3D Printing Could Change our World”, Shell Global, http://www.shell.com/ inside-energy/how-3d-printing-is-changing-the-world.html.

European Centre for Disease Prevention and Control data. Geographical distribution of 2019- nCov cases. Available online: (https://www.ecdc.europa.eu/en/geographicaldistribution-2019-ncov-cases)

EY, Global generations: A global study on work-life challenges across generations, 2015, http://www.ey.com/ Publication/vwLUAssets/EY-global-generations-a-globalstudy-on-work-life-challenges-acrossgenerations/\$FILE/ EY-global-generations-a-global-study-on-work-life-challenges-across-generations.pdf.

Ferreira Jr. et al. Simulation of Non-Isothermal Transient Flow in Gas Pipeline Networks. Rio Pipeline Conference, 2009.

Geiger, Julianne, "How Millennials Could Bring The Oil Industry To Its Knees", OilPrice, 1 September 2016, http://oilprice.com/Energy/Energy-General/How-Millennials-CouldBring-The-Oil-Industry-To-ItsKnees.html

Hill R J, Zhang E, Katz B J, et al. Modeling of gas generation from the Barnett Shale, Fort Worth Basin, Texas. AAPG Bulletin, 2007, 91(4): 501-521.

Hobday, M. Product complexity, Innovation and Industrial Organisation, Research policy, n. 26, p. 689-710, 1998.

https://www.geoexpro.com/articles/2019/07/digital-technology-trends-in-the-oil-and-gas-industry

http://www.oil-gasportal.com/innovation-and-new-technologies-in-the-upstream-oil-gas-industry/

https://www.ogj.com/home/article/17297879/digital-transformation-powering-the-oil-gas-industry

$\mathrm{Hu}$ Wenrui, Zhai Guangming. Practice and sustainable devel-opment of oil and natural gas exploration and development in Ordos Basin. Engineering Sciences, 2010, 10(5): 64-72.

Imperial College London. Report 2: estimating the potential total number of novel coronavirus cases in Wuhan City, China. Jan. disease-analysis/news-- wuhan-coronavirus, 2020.

Impacts on Work Productivity. TIJAB (The International Journal of Applied Business), 4(1), 13-21.

InnovOil, "Smart thinking - cognitive computing with Repsol", Issue 44, 30 June 2016, http://www.innovoil.co.uk/ single-post/2016/06/30/Smart-thinking-\%E2\%80\%93-cognitive-computing-withRepsol.

International Renewable Energy Agency (IRENA), The Power to Change: Solar and Wind Cost Reduction $\begin{array}{llll}\text { Potential to 2025, June 2016, } & \end{array}$ http://www.irena.org/DocumentDownloads/Publications/IRENA_Power_to_Change_2016.pdf.

Kuckertz, A., Brändle, L., Gaudig, A., Hinderer, S., Morales Reyes, C. A., Prochotta, A., Steinbrink, K. M., \& Berger, E. S. C. (2020). Startups in times of crisis - A rapid response to the COVID-19 pandemic. Journal of Business Venturing Insights, 13, e00169.

Lin, J., Li, L., Luo, X. (Robert), \& Benitez, J. (2020). How do agribusinesses thrive through complexity? The pivotal role of e-commerce capability and business agility. Decision Support Systems, 113342.

Lo, Chris, "Turning the cogs: IBM's Cognitive Environments Lab takes on offshore exploration", offshoretechnology.com, 10 March 2015, http://www.offshore-technology. com/features/featureturning-the-cogsibms-cognitive-environments-lab-takes-on-offshore-exploration-4517222/. 
Mehdi Mohammadpoor, Farshid Torabi, Big Data analytics in oil and gas industry: An emerging trend, Petroleum, 2018, ISSN 2405-6561, https://doi.org/10.1016/j.petlm.2018.11.001. (http://www.sciencedirect.com/science/article/pii/S2405656118301421)

Microsoft Internet of Things, "Fueling innovation: When stopping for gas becomes a connected, customized experience", 25 March 2015, https://blogs.microsoft.com/ iot/2015/03/25/fueling-innovation-when-stoppingfor-gasbecomes-a-connected-customized-experience/.

OECD. Open Innovation in Global Networks. Policy Brief, November, 2008.

Peiris, J. S. M., Lai S. T., Poon L. et. al. Coronavirus as a possible cause of severe acute respiratory syndrome. The Lancet, 2003; 361(9366): 1319- 1325

Qian Xingkun, Xu Jianshan, Lin Donglong, et al. Development report of oil \& gas industry home and abroad in 2011. Beijing: CNPC Economics \& Technology Institute, 2012: 163-175.

Randall, Tom, "The World Nears Peak Fossil Fuels for Electricity", Bloomberg, 13 June 2016, https://www.bloomberg. com/news/articles/2016-06-13/we-ve-almost-reachedpeak-fossil-fuels-forelectricity.

Ritter, T., \& Pedersen, C. L. (2020). Analyzing the impact of the coronavirus crisis on business models. Industrial Marketing Management, 88, 214-224.

Reeves, M., Lang, N., \& Carlsson-Szlezak, P. (2020). Lead Your Business Through the Coronavirus Crisis. In Coronavirus and Business: The Insights You Need from Harvard Business Review. Harvard Business Review.

Robinson, D. K.R. \& Propp, T. Multi-path mapping for alignment strategies in emerging science and technologies. Technological Forecasting \& Social Change 75 (2008) 517-538.

Robotic Drilling Systems, “Technology”, http://www.rds.no/ technology.

Rothwell, R. Towards Fifth-generation Process Innovation; International Marketing Review, n. 11/1, p. 7-31, 1994.

Shahan, Cynthia, "The Pragmatic Idealism Of Millennials - 76\% Of Millennials Want An Eco-Friendly Car", CleanTechnica, 21 September 2016, https://cleantechnica. com/2016/09/21/pragmatic-idealism-millennials76-millennials-want-eco-friendly-car/

Sharma, A., Rangarajan, D., \& Paesbrugghe, B. (2020). Increasing resilience by creating an adaptive salesforce. Industrial Marketing Management, 88, 238-246.

Sheth, J. (2020). Business of business is more than business: Managing during the Covid crisis. Industrial Marketing Management, 88, 261-264.

Susser, P., \& Tyson, T. (2020). What Are Companies' Legal Obligations Around Coronavirus? In Coronavirus and Business: The Insights You Need from Harvard Business Review. Harvard Business Review.

Tarki, A., Levy, P., \& Weiss, J. (2020). The Coronavirus Crisis Doesn't Have to Lead to Layoffs. In Coronavirus and Business: The Insights You Need from Harvard Business Review. Harvard Business Review.

TechTarget, "Definition: Internet of Things (IoT)", IoT Agenda, July 2016,http://internetofthingsagenda.techtarget. com/definition/Internet-of-Things-IoT.

Total, "Our Priority: To Remain at the Cutting Edge of Solar Technology", http:/www.total.com/en/energyexpertise/ exploration-production/solar-power/sunpower-solar-technology

Tse, A. C. B., So, S., \& Sin, L. (2006). Crisis management and recovery: how restaurants in Hong Kong responded to SARS. International Journal of Hospitality Management, 25(1), 3-11.

Trice, Andrew, "The Future of Cognitive Computing", IBM Bluemix Blog, 23 November 2015, https://www.ibm.com/ blogs/bluemix/2015/11/future-of-cognitive-computing/

Vorrath, Sophie, "Millennials want solar, storage, shared energy - and an app for all that", RenewEconomy, 18 August 2016, http://reneweconomy.com.au/millennials-want-solarstorage-shared-energy-and-an-app-for-allthat-42142/

Wang, Y., Hong, A., Li, X., \& Gao, J. (2020). Marketing innovations during a global crisis: A study of China firms' response to COVID-19. Journal of Business Research, 116, 214-220.

WHO (2020). Coronavirus disease 2019 (COVID-19): Situation report (No. 94).

World Bank. (2020). World Bank Open Data | Data. GDP (Current US\$) | Data. https://data.worldbank.org/indicator/NY.GDP.MKTP.CD

World Energy Council, "World Energy Scenarios 2016 report: Global energy demand growth set to fall”, 2016, https://www.worldenergy.org/news-and-media/press-releases/world-energy-scenarios-2016-report-globalenergydemand-growth-set-to-fall/.

Ying Jinghong, Lei Angui, Fang Bingzhong, et al. Concept of "seeking for oil and gas deep down depressions" in Liaohe pe-ripheral Mesozoic basin. Petroleum Exploration and Devel-opment, 2008, 35(1): 6-10.

Zenker, S., \& Kock, F. (2020). The coronavirus pandemic - A critical discussion of a tourism research agenda. Tourism Management, 81, 104164. 
Zhai Guangming, Wang Shihong. Status and strategic thinking of oil \& gas resources in China: Exploration \& development of remaining oil and gas resources by technology applied in unconvetional oil \& gas. Beijing: CNPC Advisory Centre, 2012: 21-22.

Zou Caineng, Tao Shizhen, Yuan Xuanjun, et al. Global im-portance of "continuous" petroleum reservoir: Accumulation, distribution and evaluation.Petroleum Exploration and Devel-opment, 2009, 36(6): 669-682. 